\title{
Uso de Ferramentas do Google para Ensino e Aprendizagem de Alunos com Transtorno do Espectro Autista da APAE na cidade de Caicó-RN
}

\author{
Angélica F. Medeiros' ${ }^{1}$ Adnama L. G. Costa ${ }^{1}$, Eduardo V. de A. Germano', \\ Nathalia G. P. Alves ${ }^{1}$ \\ ${ }^{1}$ Departamento de Computação e Tecnologia \\ Universidade Federal do Rio Grande do Norte (UFRN) - Caicó, RN - Brasil \\ \{angelicafelixx, adnama.lins.g, dudu.germano15, \\ nathalia.giulliane\} @gmail.com
}

\begin{abstract}
The present research has the objective of investigating and verifying the teaching and learning process with professionals from the Associação de Pais e Amigos dos Excepcionais (APAE) and students with Autism Spectrum Disorder (TEA), through the creation of Comic Books using the tools Google Drive to analyze the usability and impact of this application in reading and writing.
\end{abstract}

Resumo. A presente pesquisa tem o objetivo de investigar e verificar o processo de ensino e aprendizagem com profissionais da Associação de Pais e Amigos dos Excepcionais (APAE) e alunos com Transtorno do Espectro Autista (TEA), através da criação de Histórias em Quadrinhos utilizando as ferramentas do Google Drive, a fim de analisar a usabilidade e impacto desta aplicação no ensino de leitura e escrita.

\section{Introdução}

A utilização de Tecnologias de Informação e Comunicação (TIC) é um fato bastante popular na sociedade contemporânea, principalmente devido ao baixo custo dos recursos tecnológicos (SANTOS, 2014). O Autor reforça ainda que o ambiente educacional também é alvo de inserção das tecnologias, proporcionando aos professores e alunos diferentes possibilidades de interação com a informação, fortalecendo a construção do conhecimento de modo significativo. Esse contexto se faz importante para contribuir também na educação de portadores de Necessidades Educativas Especiais (NEE), visando os benefícios que as TIC proporcionam.

No entanto, se faz necessário avaliar a usabilidade, verificar os princípios necessários para um software de qualidade e verificar se é possível desenvolver o convívio dos alunos Autistas e o compartilhamento das atividades, facilitando o trabalho em equipe. Neste sentido, será investigada a usabilidade da ferramenta colaborativa Google Drive visando tornar mais eficiente o processo de ensino aprendizagem de alunos com Transtorno do Espectro Autista (TEA) da Associação de Pais e Amigos dos Excepcionais (APAE) em Caicó-RN. Nesse cenário, serão desenvolvidas e aplicadas atividades relacionadas a criação, leitura, interpretação e compartilhamento de histórias em quadrinhos. Assim, será examinado como as ferramentas do Google Drive podem contribuir na educação de portadores do TEA. 
VII Congresso Brasileiro de Informática na Educação (CBIE 2018)

Anais do XXIX Simpósio Brasileiro de Informática na Educação (SBIE 2018)

\section{Estado da Arte}

As Tecnologias de Informação e Comunicação (TIC) têm sido utilizadas no contexto da educação especial tendo em vista a sua potencialidade na colaboração do ensino, onde acarreta benefícios imensuráveis, já que é notável a dificuldade de ensino para portadores de deficiência, neste sentido, toda e qualquer forma de ensino que contribua para essa área é bem-vinda.

Dentre as TIC, este trabalho aborda o uso de ferramentas colaborativas e neste sentido, Brito et al.(2016) destacam ainda que os benefícios desta aplicação voltada para a educação especial oferecem, tanto no contexto social, quanto na inclusão, já que com esse tipo de tecnologia o portador de deficiência tem um suporte a mais para auxiliá-lo na busca pelo conhecimento e especialmente passa a ter uma maior acessibilidade.

Nesse sentido, Abegg, Bastos e Muller (2010) ressaltam que as ferramentas colaborativas incluem outras perspectivas ao processo de ensino-aprendizagem, disponibilizando novas maneiras de realizar as atividades educacionais, acrescentando medidas como planejamento colaborativo e funcionalidades específicas, nos quais os envolvidos podem executar tarefas na internet de modo colaborativo.

No contexto dos trabalhos relacionados, destaca-se o trabalho de Silva et al. (2017), pois estes realizaram um mapeamento sistemático da literatura com propósito de investigar as tendências dos avanços no uso de tecnologias computacionais para $o$ ensino de portadores de TEA e afirmam ainda a presença de diversas dificuldades de aprendizado e alfabetização, onde as tecnologias computacionais podem contribuir para o desenvolvimento de crianças com autismo. Outro interessante resultado foi apontado no trabalho de Moura et al. (2014), que apresentam uma ferramenta colaborativa com o propósito de apoiar o processo de ensino-aprendizagem da LIBRAS e do português para alunos surdos.

Diante destes aspectos, o presente trabalho destaca-se pela perspectiva de avaliação do uso de ferramentas colaborativas do Google, visando viabilizar o uso destas no processo de ensino-aprendizagem dos portadores do Transtorno do Espectro Autista.

\section{Percurso Metodológico}

Esta pesquisa faz parte de um projeto em andamento, que de modo geral tem o propósito de aplicar atividades relacionadas a criação, leitura, interpretação e compartilhamento de histórias em quadrinhos através das ferramentas do Google Drive e avaliar a eficácia desta no processo de ensino aprendizagem de alunos portadores do TEA. A pesquisa visa ainda, avaliar aspectos relacionados a usabilidade.

Nesta fase da pesquisa apresentada no presente trabalho, foram realizadas reuniões com os pedagogos e profissionais que compõem o Atendimento Educacional Especializado (AEE) da APAE com o intuito de validar a proposta através de uma avaliação piloto. A proposta em análise envolvia o uso das ferramentas colaborativas mencionadas anteriormente através da criação de histórias em quadrinhos e a avaliação da usabilidade destas através de questionários.

A ferramenta Google Drive foi utilizada como um estilo de framework para possibilitar e facilitar a criação de histórias em quadrinhos. Estão armazenadas pastas 
VII Congresso Brasileiro de Informática na Educação (CBIE 2018)

Anais do XXIX Simpósio Brasileiro de Informática na Educação (SBIE 2018)

compartilhadas, compostas por diversas imagens como planos de fundo, personagens e objetos que dessem para fazer uma narrativa da história.

\section{Resultados Preliminares}

Inicialmente, foi realizado uma avaliação piloto para validação do questionário que será aplicado posteriormente aos portadores de TEA, o questionário foi validado pelos profissionais da Associação de Pais e Amigos dos Excepcionais (APAE) em Caicó RN, por conter diversos emoticons, ilustrados na Figura 1, para que os envolvidos possam demonstrar seus sentimentos e/ou opiniões relacionadas à utilização da ferramenta.

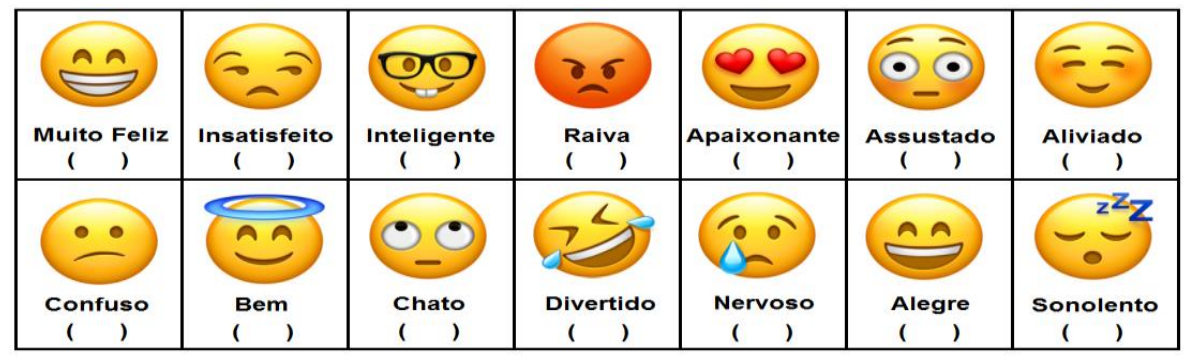

Figura 1. Emoticons utilizados nos questionários. Fonte: Próprio autor com base no emojipedia.

Os profissionais da APAE também aprovaram o uso das histórias em quadrinhos e na Figura 2 é possível visualizar como estão sendo realizadas as atividades relacionadas a criação de histórias em quadrinhos com o intuito de colaborar com o processo de leitura e escrita dos portadores de TEA. De acordo com Kawamoto e Campos (2014), histórias em quadrinhos envolvem diversos aspectos, entres eles estão visuais, cognitivos e criativos, que oferecem diversas formas de complementar os conteúdos utilizados na sala de aula.
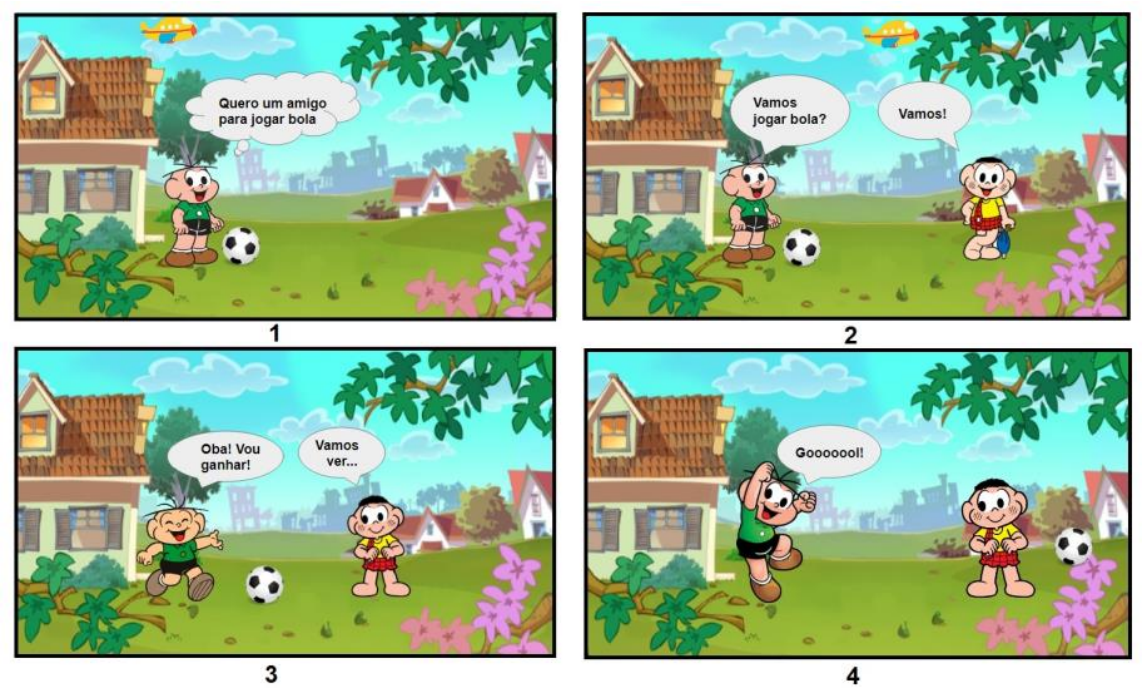

Figura 2. Imagem da criação de Histórias em Quadrinhos no Google Drive

Diante dos passos realizados até o momento a pesquisa apresenta pontos positivos relacionados a validação dos questionários e utilização das histórias em quadrinhos, como também a usabilidade e intuitividade da ferramenta, assim como a satisfação dos usuários ao fazer uso desta. 
VII Congresso Brasileiro de Informática na Educação (CBIE 2018)

Anais do XXIX Simpósio Brasileiro de Informática na Educação (SBIE 2018)

\section{Conclusão}

Este trabalho faz parte de uma pesquisa maior em andamento, espera-se como contribuição que a pesquisa contribua para o processo de ensino-aprendizagem de portadores do Transtorno do Espectro Autista e que possibilite uma maior interação entre os indivíduos, o que se torna fundamental para ajudar o portador de TEA em seu meio social.

Como trabalho futuro serão confeccionadas mais histórias em quadrinhos que serão aplicadas em sala de aula com o apoio dos pedagogos da instituição tendo como abordagem de pesquisa um estudo de caso. Posteriormente, serão aplicados os questionários e os resultados serão analisados e discutidos, visando identificar pontos positivos e negativos da inserção e utilização da tecnologia na educação, através do uso de ferramentas colaborativas para validar essa proposta.

\section{Referências}

ABEGG, Ilse; BASTOS, Fábio da Purificação de; MÜLLER, Felipe Martins. Ensinoaprendizagem colaborativo mediado pelo wiki do Moodle. Educar em Revista, n. 38, 2010 .

BRITO, Rozimar Rodrigues de et al. Tecnologias Assistivas na Educação: Ferramentas Facilitadoras de Inclusão Digital. In: II Congresso internacional de educação inclusiva, 2016.

KAWAMOTO, Elisa Mári; CAMPOS, Luciana Maria Lunardi. Histórias em quadrinhos como recurso didático para o ensino do corpo humano em anos iniciais do Ensino Fundamental. Ciência \& Educação (Bauru), v. 20, n. 1, 2014.

MOURA, Elton Raniere da S. et al. Uma ferramenta colaborativa móvel para apoiar o processo de ensino-aprendizagem da LIBRAS e do Português para surdos. In: Anais dos Workshops do Congresso Brasileiro de Informática na Educação. 2014. p. 272.

SANTOS, Clodogil Fabiano Ribeiro dos. Tecnologias de informação e comunicação. Unicentro, Paraná. 2014.

SILVA, Martony Demes da et al. Uso de tecnologias computacionais para o ensino de crianças com Transtorno do Espectro Autista: Um mapeamento sistemático da literatura. In: Brazilian Symposium on Computers in Education (Simpósio Brasileiro de Informática na Educação-SBIE). 2017. p. 173. 